\title{
Sleep Quality and Associated Factors Among
} Diabetes Mellitus Patients in a Follow-Up Clinic at the University of Gondar Comprehensive

\section{Specialized Hospital in Gondar, Northwest Ethiopia: A Cross-Sectional Study}

This article was published in the following Dove Press journal:

Diabetes, Metabolic Syndrome and Obesity: Targets and Therapy

\section{Tesfamichael Tadesse Birhanu' Mohamed Hassen Salih (iD ${ }^{2}$ Hailemichael Kindie Abate ${ }^{2}$ \\ 'Department of Medical Nursing, University of Gondar Comprehensive Specialized Hospital, Gondar, Ethiopia; ${ }^{2}$ Department of Medical Nursing, School of Nursing, College of Medicine and Health Science, University of Gondar, Gondar, Ethiopia}

Introduction: Diabetic mellitus has a negative impact on the quality of sleep. It is one of the leading public health conditions which can result in poor sleep quality. Poor sleep quality is an unreported and unrecognized problem which can affect the prognosis of diabetes patients.

Objective: The aim of this study is to assess the prevalence of poor sleep quality and its associated factors among patients with diabetes mellitus attending follow-up clinics at the University of Gondar Comprehensive Specialized Hospital, Northwest Ethiopia, 2019.

Methods: An institution-based cross-sectional study was conducted among 430 diabetes mellitus patients at the University of Gondar Comprehensive Specialized Hospital from February 1, 2020 to March 28, 2020. A systematic random sampling method was used to reach the study subjects. An interviewer-administered questionnaire was used for data collection. Pittsburgh sleep quality index was used for assessing sleep quality. To explain study variables, frequency tables and percentages were used. A binary logistic regression was conducted to see the relation between dependent and independent variables.

Results: A total of 430 diabetes mellitus patients participated in the study with a response rate of $100 \%$. The overall prevalence of poor sleep quality was $47.2 \%$. Drinking alcohol (AOR $=2.45$, 95\% CI: $1.28-4.69$ ), smokers ( $\mathrm{AOR}=6.26,95 \% \mathrm{CI}: 2.04-19.21)$, comorbidity (AOR $=1.80,95 \%$ CI: $1.10-2.96), \mathrm{BMI} \geq 30(\mathrm{AOR}=4.87,95 \% \mathrm{CI}: 1.07-22.09)$, having type 2 diabetes mellitus $(\mathrm{AOR}=2.16,95 \% \mathrm{CI}: 1.04-4.50)$, poor glycemic control $(\mathrm{AOR}=2.61,95 \% \mathrm{CI}: 1.81-4.81)$ and having depression ( $\mathrm{AOR}=9.95,95 \% \mathrm{CI}$ : 4.85-20.38) were associated with poor sleep quality.

Conclusion: In this study, nearly half of the patients had poor sleep quality. Drinking alcohol, smoking, comorbidities, higher BMI, type 2 diabetes mellitus, poor glycemic control and having depression were factors in poor sleep quality. Creating awareness of the need for weight reduction, minimizing alcohol intake, cessation of smoking, and improving sleep hygiene for DM patients would be effective management for improving poor sleep quality. Keywords: diabetes mellitus, sleep disturbance, sleep quality, Gondar, Ethiopia

\section{Introduction}

Diabetes mellitus (DM) is a metabolic disease that presents with the prolonged raising of blood glucose levels with the disorder of carbohydrate, fat and protein metabolism due to problems in insulin production, insulin function or both. ${ }^{1}$
Correspondence: Hailemichael Kindie Abate

Email haile206k@gmail.com 
Globally, there is a growing burden of DM due to factors such as increasing age, urbanization, obesity, and physical inactivity. ${ }^{2}$ Worldwide the magnitude of diabetes in 2019 was estimated as $9.3 \%$ (463 million individuals), rising to $10.2 \%$ (578 million individuals) by 2030 and $10.9 \%$ (700 million individuals) by 2045 . Diabetes is a challenge for millions of people in both developed and developing countries. ${ }^{3}$ vidence in Ethiopia showed that an estimated $3.8 \%$ of the population had DM. ${ }^{4}$

Sleep is essential for life and maintenance of body functions. During sleep the body secretes many important hormones to regulate metabolic and endocrine functions. ${ }^{5-7}$ The main role of sleep is to restore a whole body's balance, including the central nervous system, and it is a daily requirement. ${ }^{8}$

Good sleep quality has a significant clinical importance in diabetes mellitus patients by regulating the level of insulin, the build-up of inflammatory cytokines, preserving body caloric intake, and decreasing the likelihood of unhealthy behavior. ${ }^{9}$

Poor sleep quality is a leading health problem in the diabetic population. It presents as symptoms characterized by difficulty in initiating and maintaining sleep, excessive somnolence, disturbed sleep-wake schedule and dysfunctions associated with sleep and sleep stages. ${ }^{10}$ Poor sleep quality is a medical disorder of the sleep patterns with higher rates of poor sleep quality, excessive daytime sleepiness, and higher use of sleep medications. ${ }^{11}$

Evidence shows that poor sleep quality is a common problem among people with diabetes mellitus. ${ }^{11-13}$ Globally, $47.6 \%$ of diabetics were affected by poor sleep quality. ${ }^{14}$ In Africa, $29.5 \%$ of the diabetic population presented sleep disturbance. ${ }^{15}$ A study done in Ethiopia showed that about $55.6 \%$ of diabetic patients were affected by sleep disturbance. ${ }^{16}$

Poor sleep quality in DM patients can be due to decreases in saturation level, pain, restless leg syndrome, nocturnal polyuria, and nocturnal hypoglycemia. ${ }^{17}$ Poor sleep quality may bring about mental impairment and decrease the working capacity of individuals with DM. Evidence shows that poor sleep quality among DM patients was associated with factors such as age, gender, body mass index, noisy environments, smoking and drinking habits. ${ }^{18}$

Poor sleep quality in DM patients can lead to nonadherence to their recommended medication, insulin resistance, cardiovascular disease, mental impairment and decreases in working capacity. ${ }^{11-13,18}$ It also impairs cognitive performance, and can lead to a higher risk of stroke and depression. ${ }^{19}$

Reducing preventable mortality from noncommunicable diseases (NCDs) including DM by $25 \%$ is a target of the World Health Organization (WHO) by the end of 2025. Tackling poor sleep quality has been identified as one key measure for achieving this target. ${ }^{20}$ Simultaneous occurrence of poor sleep quality with DM makes clinical management more complicated. Hence, understanding the magnitude and major risk factors are a key role of health-care providers to prevent, identify and treat poor sleep quality.

So far as the researchers are aware, there was no research done in the study area. Therefore, conducting this study was able to give evidence on the prevalence as well as major factors of poor sleep quality. Determining the risk factors of poor sleep quality is important for its urgent management and further reduction of health-care costs related to the care needed.

The results of this study will provide information for health-care providers and policymakers as a baseline for further study.

Therefore, this study assessed the prevalence of poor sleep quality and its associated factors among adults with diabetes mellitus attending a follow-up clinic at the University of Gondar Comprehensive Specialized Hospital (UOCGSH), Northwest Ethiopia.

\section{Methods}

\section{Study Design and Period}

A cross-sectional institutional-based study was conducted from February 1, 2020 to March 28, 2020.

\section{Study Area}

The study was conducted at the UOGCSH diabetes followup clinic. The hospital is located in Gondar town, Amhara regional state, $748 \mathrm{~km}$ away from Addis Ababa. The UOGCSH has more than 14 outpatient medical service units and more than 250,000 people have visited the services. Chronic illness care is one of the services that the hospital provides to the population who are living in and outside of Gondar town. Provision of follow-up and treatments for DM patients is one of the services offered in the chronic illness care clinic. Besides, the hospital serves as a tertiary level referral center for over seven million people in Gondar town and Northwest Ethiopia. ${ }^{21}$ 


\section{Source and Study Population}

All adult DM patients attending DM clinics at the UOGSH were the source population, whereas all DM patients attending the follow-up clinics during the study period were the study population.

\section{Inclusion and Exclusion Criteria}

All diabetes patients having follow-up at the hospital during the study period were included in this study, whereas patients who were seriously ill, or who had a diagnosed psychiatric disorder were excluded from the study.

\section{Sample Size Determination and Sampling Procedure}

The sample size of the first objective was calculated by using single population proportion formula $n=\left(\mathbf{Z} \frac{\alpha}{2}\right) 2 * \mathbf{p}(1-\mathbf{p}) /(\mathbf{d}) 2$. From the formula "n" denotes sample size, " $\frac{\alpha}{2}$ " is the reliability coefficient of standard error at the $5 \%$ level of significance with $\mathrm{z}=1.96$, "p" is proportion and "d" is level of standard error. The prevalence (p) used was $55.6 \%$, which was taken from a previous study done in Ethiopia, ${ }^{16}$ to determine the sample size of 379 and $10 \%$ non-response rate was taken to determine the total sample size of 417 . The sample size of the second objective was calculated using STATCalc Epi info version 7 by taking a proportion of factors from a similar study conducted in Ethiopia. ${ }^{22}$ The largest sample size calculated from the second objective was 391, which was higher than the first objective and $10 \%$ of nonresponse rate was taken to determine the final sample size of 430 (see Table S1).

There were nearly 600 diabetic patients attending the outpatient department per month. A systematic random sampling technique was employed to select the study participants with every one interval. To avoid the recycling of data, special marks were used for the interviewed patients' charts to indicate whether they had participated or not in the previous visit.

\section{Operational Definitions}

Sleep quality: The Pittsburgh Sleep Quality Index (PSQI) classifies a global score of $>5$ as indicating clients have poor sleeping quality, whereas a global score $\leq 5$ is classified as good sleeping quality. ${ }^{23}$

Duration of diabetes mellitus: Duration of $\leq 10$ years since the first diagnosis is considered short duration and $>$ 10 years is considered to be long duration. ${ }^{16}$
Poor glycemic control: The average fasting blood glucose on three consecutive visits is $>130$ or less than $70 \mathrm{mg} / \mathrm{dl}^{24}$

Good glycemic control: A 3-month average fasting blood glucose was between 70 and $130 .^{24}$

Depression: A total score of $>10$ points with PHQ-9 scale, was categorized to indicate depressive symptoms. ${ }^{25}$

Anxiety: Study participants who scored 9 and above on the generalized anxiety disorder items of the questionnaire were categorized to have anxiety. ${ }^{26}$

Comorbidity: The presence of one or more distinct medical problems in an individual along with $\mathrm{DM}^{27}$

BMI: A person was classified as underweight (BMI < $18.5 \mathrm{~kg} / \mathrm{m}^{2}$ ), normal body weight (BMI 18.5-24.9 kg/ $\mathrm{m}^{2}$ ), overweight (BMI $25-29.9 \mathrm{~kg} / \mathrm{m}^{2}$ ), or obese (BMI $\left.\geq 30 \mathrm{~kg} / \mathrm{m}^{2}\right){ }^{28-30}$

Smoking: Currently smoking is smoking a cigarette at least once within the last 30 days. ${ }^{16,24}$

Drinking alcohol: Patients were classified as drinking alcohol if they had a history of consuming an alcoholic drink since the last visit. ${ }^{24,31}$

Chewing khat: Current chewer is a patient who had a history of khat chewing in the past one month. ${ }^{16,32}$

\section{Data Collection Tools and Procedures}

A structured interviewer-administered questionnaire was adapted from other related studies to collect the data. ${ }^{25,33}$ The questionnaire has three parts, which includes sociodemographic factors, Pittsburgh sleeping quality index (PSQI) and factors that affect sleep quality including psychosocial, behavioral, and clinical factors. Sleep quality was assessed by the PSQI scale with 19 items, which has seven subscales. The sum of scores for these seven components yields one global PSQI score. Each component of the PSQI has a score from 0 to 3 . The sum of the score ranges from 0 to 21, in which the higher scores indicate poor sleep quality and the lower scores indicate good sleep quality. ${ }^{33}$ The level of depression is assessed using a nine item Patient Health Questionnaire (PHQ-9), which was validated in Ethiopia. Each component has a score of 0 to 3 with a global score ranging from 0 to 27 . A total score of more than 10 indicates the presence of depressive symptoms. ${ }^{25}$ The Cronbach's alpha for PSQI and depression items were 0.73 and 0.80 respectively. The generalized anxiety disorder section with 7 items was used to screen participants' levels of anxiety; it has an internal reliability in Ethiopia of $0.91 .^{34}$ Before the actual data collection, four BSc nurse data collectors and one MSc 
nurse acting as a supervisor had obtained a half day of training about the aim of the study and the content of the overall questionnaire.

\section{Data Quality Assurance}

To maintain data quality, a pre-test was done on $22(5 \%)$ diabetes patients from Felege Hiwot Referral Hospital. A structured interviewer administered questionnaire was used to collect the data. The questionnaire was prepared in English and translated to local language Amharic for the sake of better understanding for the study participants. The data were checked for completeness during the data collection, entry, and analysis process.

\section{Data Processing and Analysis}

The collected data were checked for completeness and accuracy before analysis. The data were exported to Statistical Package for Social Science (SPSS) version 20 software for analysis. The data were then re-coded, and cleaned with appropriate statistical analysis using SPSS. Descriptive statistics such as the frequency and percentage were used. Tables and graphs were used to describe the sample characteristics and response to questionnaire items. Model fitness was checked using the Hosmer-Lemeshow goodness of fit test $(\mathrm{p}=0.26)$ and interpreted as a model fitted. All variables fulfilled the chi-square assumption and the odds ratio checked. Multicollinearity was checked using variance inflation factor (VIF) and its values were between 1-10, which was interpreted as no multicollinearity. Bivariable and multivariable logistic regression analyses were used to identify associated factors. Those variables with p-value less than 0.2 in bivariable analysis were entered into multivariable analysis. The backward selection process was used to see the final associated variables. Those variables with $\mathrm{p}$-value less than 0.05 with $95 \%$ confidence interval were considered as significantly associated with outcome variables.

\section{Results}

\section{Socio-Demographic Characteristics}

A total of $430 \mathrm{DM}$ clients participated in the study with a response rate of $100 \%$.

The mean age of participants was 51.23 with standard deviation (SD) of 15.19 years. More than half, 238 $(55.3 \%)$ were female participants and $274(63.7 \%)$ of them were married. The majority, $363(83.5 \%)$ of the participants were Christian, and $102(23.7 \%)$ of the participants had attended primary school. About 331 (77\%) of the participants lived in urban areas and 130 (30.2\%) were a housewife. The majority, $372(86.5 \%)$ of them were living within the family (Table 1).

\section{Clinical Characteristics}

Less than half, 181 (42.1\%) participants had confirmed DM since 1-4 years back. More than half, 231 (53.7\%) of the participants had a normal body mass index (BMI). The majority, $329(76.5 \%)$ of the participants were type 2 DM. More than half, 247 (57.4\%) of the participants had

Table I Socio-Demographic Characteristics of Patients with DM at a Follow-Up Clinic at the UoGCSH, $2020(n=430)$

\begin{tabular}{|c|c|c|c|}
\hline Variables & Category & $\begin{array}{l}\text { Frequency } \\
\text { (n) }\end{array}$ & $\begin{array}{l}\text { Percent } \\
\text { (\%) }\end{array}$ \\
\hline \multirow[t]{2}{*}{ Sex } & Female & 238 & 55.3 \\
\hline & Male & 192 & 44.7 \\
\hline \multirow[t]{5}{*}{ Age group } & 18-29 & 46 & 10.7 \\
\hline & $30-39$ & 44 & 10.2 \\
\hline & $40-49$ & 79 & 18.4 \\
\hline & $\geq 50$ & 261 & 60.7 \\
\hline & Mean/SD of age & 51.23 Mean & $S D \pm 15.19$ \\
\hline \multirow{4}{*}{$\begin{array}{l}\text { Marital } \\
\text { status }\end{array}$} & Single & 74 & 17.2 \\
\hline & Married & 274 & 63.7 \\
\hline & Divorced & 35 & 8.1 \\
\hline & Widowed & 47 & 10.9 \\
\hline \multirow[t]{2}{*}{ Religion } & Christianity & 363 & 84.4 \\
\hline & Muslim & 67 & 15.6 \\
\hline \multirow[t]{5}{*}{ Education } & $\begin{array}{l}\text { Cannot read and } \\
\text { write }\end{array}$ & 55 & 12.8 \\
\hline & Read and write & 94 & 21.9 \\
\hline & Primary school & 102 & 23.7 \\
\hline & Secondary school & 88 & 20.5 \\
\hline & College and above & 91 & 21.2 \\
\hline \multirow[t]{2}{*}{ Residence } & Urban & 331 & 77.0 \\
\hline & Rural & 99 & 23.0 \\
\hline \multirow[t]{6}{*}{ Occupation } & $\begin{array}{l}\text { Government } \\
\text { employee }\end{array}$ & 107 & 24.9 \\
\hline & Farmer & 21 & 4.9 \\
\hline & Housewife & 130 & 30.2 \\
\hline & Merchant & 34 & 7.9 \\
\hline & Private work & 82 & 19.1 \\
\hline & Others* & 57 & 13.3 \\
\hline \multirow{3}{*}{$\begin{array}{l}\text { Living } \\
\text { statues }\end{array}$} & Alone & 44 & 10.2 \\
\hline & With family & 372 & 86.5 \\
\hline & With non-family & 14 & 3.3 \\
\hline
\end{tabular}

Notes: Others*, daily labor, unemployed student.

Abbreviations: DM, diabetes mellitus; UoGCSH, University of Gondar Comprehensive Specialized Hospital; SD, standard deviation. 
poor controlled fasting blood glucose. Almost half, 212 $(49.3 \%)$ used an oral hypoglycemic-based regimen. Fiftyseven percent of study participants had comorbidity and almost half, 187 (47.3\%) of the participants had comorbidity with hypertension (Table 2).

\section{Psychosocial and Behavioral Characteristics}

About 156 (36.3\%) of the participants had depression. Of the total participants, 178 (41.4\%) had anxiety. Regarding behavioral habits, about $6(1.4 \%)$ were khat chewers, 65 (15.1\%) drank alcohol and $6(1.4 \%)$ participants were past smokers (Table 3).

\section{Prevalence of Sleep Quality}

The overall prevalence of poor sleep quality among diabetic patients was $47.2 \%$ (95\% CI: 42.5-52.1), whereas the prevalence of good sleep quality was $52.8 \%$ (95\% CI:

Table 2 The Clinical Characteristics of Patients with DM at a Follow-Up Clinic at the UoGCSH, $2020(n=430)$

\begin{tabular}{|l|l|l|l|}
\hline Variables & Category & $\begin{array}{l}\text { Number } \\
\text { (n) }\end{array}$ & $\begin{array}{l}\text { Percent } \\
\text { (\%) }\end{array}$ \\
\hline $\begin{array}{l}\text { Duration of DM } \\
\text { in year }\end{array}$ & $\begin{array}{l}\text { I-4 year } \\
5-10 \text { year } \\
>10\end{array}$ & $\begin{array}{l}181 \\
163 \\
86\end{array}$ & $\begin{array}{l}42.1 \\
37.9 \\
20.0\end{array}$ \\
\hline $\begin{array}{l}\text { History of } \\
\text { comorbidity }\end{array}$ & Yes & 249 & 57.9 \\
\hline Type of comorbidity & No & 181 & 42.1 \\
& CHF & 187 & 47.3 \\
& Both & 35 & 2.6 \\
& Others* & 16 & 3.1 \\
\hline Type of DM & Type I & 101 & 23.5 \\
& Type 2 & 329 & 76.5 \\
\hline Glycemic control & Good & 183 & 42.6 \\
& Poor & 247 & 57.4 \\
\hline Treatment modalities & Oral & 212 & 49.3 \\
& Insulin & 159 & 37.0 \\
& Both & 59 & 13.7 \\
\hline BMI & Underweight & 19 & 4.4 \\
& Normal & 137 & 31.9 \\
\hline Overweight & 231 & 53.7 \\
& Obese & 43 & 10.0 \\
\hline
\end{tabular}

Notes: Others*, kidney failure, epilepsy, stroke.

Abbreviations: DM, diabetes mellitus; UoGCSH, University of Gondar Comprehensive Specialized Hospital; BMl, body mass index; CHF, congestive heart failure; DM, diabetics mellitus; HTN, hypertension.
Table 3 The Psychosocial and Behavioral Characteristics of Patients with DM at a Follow-Up Clinic at the UoGCSH, 2020 $(n=430)$

\begin{tabular}{|l|l|l|l|}
\hline Variables & Category & $\begin{array}{l}\text { Number } \\
\text { (n) }\end{array}$ & $\begin{array}{l}\text { Percent } \\
\text { (\%) }\end{array}$ \\
\hline Depression & $\begin{array}{l}\text { Yes } \\
\text { No }\end{array}$ & $\begin{array}{l}156 \\
274\end{array}$ & $\begin{array}{l}36.3 \\
63.7\end{array}$ \\
\hline Anxiety & Yes & 178 & 41.4 \\
& No & 252 & 58.6 \\
\hline Khat chewing & $\begin{array}{l}\text { Current } \\
\text { chewer } \\
\text { Past chewer } \\
\text { Never chewer }\end{array}$ & $\begin{array}{l}18 \\
406\end{array}$ & $\begin{array}{l}1.4 \\
94.4\end{array}$ \\
\hline Smoking & $\begin{array}{l}\text { Never smoke } \\
\text { Currently } \\
\text { smoking }\end{array}$ & 390 & 90.7 \\
Past smoker & 34 & 1.4 \\
\hline Drinking alcohol & $\begin{array}{l}\text { Yes } \\
\text { No }\end{array}$ & 65 & 7.9 \\
\hline Use of hashish and & $\begin{array}{l}\text { Yes } \\
\text { No }\end{array}$ & 0 & 8365 \\
\hline
\end{tabular}

Abbreviations: DM, diabetes mellitus; UoGCSH, University of Gondar Comprehensive Specialized Hospital.

42.3-52.3). Among the total participants, 134 (31.1\%) them rated their overall sleep quality as bad. Below onethird $(22.6 \%)$ of the participants had faced 31-60 minute sleep latency. Almost half, 211 (49.1\%) of the participants had greater than 7 hours sleep duration per night. The average bedtime of the participants was 10:04 p.m. Almost two-thirds, 272 (63.3\%) of the participants had > $85 \%$ sleep efficacy. Almost all, 425 (98.8\%) participants had never used sleeping medication for their sleep disturbance and almost half, $214(49.8 \%)$ of the participants reported that their sleep quality affects their day-to-day function (Table 4).

\section{Factors Associated with Sleep Disturbance}

In multivariable regression analysis, seven variables, drinking alcohol, smoking, high BMI, comorbidities, type $2 \mathrm{DM}$, poor glycemic control and depression were significantly associated with poor sleep quality. In this study the odds of poor sleeping quality was 2.45 times $(\mathrm{AOR}=2.45$, 95\% CI: 1.28-4.69) more likely in patients who drank alcohol than those who did not. Cigarette smoking was 6.26 times (AOR $=6.26,95 \%$ CI: $2.04-19.21$ ) the odds of poor sleeping quality than non-cigarette smoking. The 
Table 4 Characteristics of Sleep Disturbance Among Patients with DM at a Follow-Up Clinic at the UoGCSH, $2020(n=430)$

\begin{tabular}{|c|c|c|c|}
\hline Variables & Category & $\begin{array}{l}\text { Frequency } \\
\text { (n) }\end{array}$ & $\begin{array}{l}\text { Percent } \\
\text { (\%) }\end{array}$ \\
\hline $\begin{array}{l}\text { Subjective sleep } \\
\text { quality }\end{array}$ & $\begin{array}{l}\text { Very good (0) } \\
\text { Fairly good (I) } \\
\text { Fairly bad (2) } \\
\text { Very bad (3) }\end{array}$ & $\begin{array}{l}187 \\
109 \\
78 \\
56\end{array}$ & $\begin{array}{l}43.5 \\
25.3 \\
18.1 \\
13.0\end{array}$ \\
\hline Sleep latency & $\begin{array}{l}0-15 \text { minutes }(0) \\
16-30 \text { minutes }(1) \\
31-60 \text { minutes }(2) \\
>60 \text { minutes }(3)\end{array}$ & $\begin{array}{l}86 \\
236 \\
97 \\
11\end{array}$ & $\begin{array}{l}20.0 \\
54.9 \\
22.6 \\
2.6\end{array}$ \\
\hline Sleep duration & $\begin{array}{l}>7 \text { hours } \\
6-7 \text { hours } \\
5-6 \text { hours } \\
<5 \text { hours }\end{array}$ & $\begin{array}{l}211 \\
90 \\
81 \\
48\end{array}$ & $\begin{array}{l}49.1 \\
20.9 \\
18.8 \\
11.2\end{array}$ \\
\hline Sleep efficacy & $\begin{array}{l}\geq 85 \% \\
75-84 \% \\
65-74 \% \\
<65 \%\end{array}$ & $\begin{array}{l}272 \\
46 \\
82 \\
30\end{array}$ & $\begin{array}{l}63.3 \\
10.7 \\
49.1 \\
7.0\end{array}$ \\
\hline Sleep disturbance & $\begin{array}{l}\text { Never }(0) \\
\text { I times a week (I) } \\
\text { I-2 times a week } \\
\text { (2) } \\
\geq 3 \text { times a week (3) }\end{array}$ & $\begin{array}{l}39 \\
328 \\
58 \\
5\end{array}$ & $\begin{array}{l}9.1 \\
76.3 \\
13.5 \\
1.2\end{array}$ \\
\hline $\begin{array}{l}\text { Used sleep } \\
\text { medication }\end{array}$ & $\begin{array}{l}\text { Never }(0) \\
\text { I-2 once a week } \\
\text { (I) }\end{array}$ & $\begin{array}{l}425 \\
5\end{array}$ & $\begin{array}{l}98.8 \\
1.2\end{array}$ \\
\hline Daytime dysfunction & $\begin{array}{l}\text { No problem (0) } \\
\text { I-2 times a week } \\
\text { (I) } \\
3 \text { times a week (2) } \\
>3 \text { times a week (3) }\end{array}$ & $\begin{array}{l}216 \\
69 \\
89 \\
56\end{array}$ & $\begin{array}{l}50.2 \\
16.0 \\
\\
20.7 \\
13.0\end{array}$ \\
\hline Overall sleep quality & $\begin{array}{l}\text { Good } \\
\text { Poor }\end{array}$ & $\begin{array}{l}227 \\
203\end{array}$ & $\begin{array}{l}52.8 \\
47.2\end{array}$ \\
\hline
\end{tabular}

Abbreviations: DM, diabetes mellitus; UoGCSH, University of Gondar Comprehensive Specialized Hospital.

odds of poor sleeping quality was 1.8 ( $\mathrm{AOR}=1.80,95 \%$ CI: 1.09-2.96) times more likely in patients with comorbidities as compared with no comorbidities. Patients with type 2 DM were 2.16 times (AOR $=2.16,95 \%$ CI: $1.04-$ 4.48) more likely to have poor sleep quality as compared with type $1 \mathrm{DM}$ patients. Having poor glycemic control was 2.61 times $(\mathrm{AOR}=2.61,95 \% \mathrm{CI}: 1.81-4.81)$ the odds of poor sleep quality than good glycemic control. Patients with depression were 9.93 times $(\mathrm{AOR}=9.93,95 \% \mathrm{CI}$ : 4.84-20.38) more likely to have poor sleeping quality as compared with their counterparts. The odds of poor sleep quality was 5 times $(\mathrm{AOR}=5.01,95 \% \mathrm{CI}: 1.10-22.86$ ) more likely in patients with a BMI $\geq 30 \mathrm{~kg} / \mathrm{m}^{2}$ as compared with patients with lower BMIs (Table 5).

\section{Discussion}

Poor sleep quality is a serious problem for DM patients since it increases risk of insulin resistance and complications related to DM. Better sleep management can increase the likelihood of better diabetes management and good management of DM can improve sleep quality. ${ }^{35}$

In this study, the overall prevalence of poor sleep quality among DM was found to be $47.2 \%$ with $95 \% \mathrm{CI}$ (42.5-52.1). The finding of this study was lower than studies conducted in Ethiopia $(55.6 \%){ }^{33}$ Kenya $(53.4 \%),{ }^{15}$ USA $(80 \%),{ }^{36}$ another similar study in the USA $(84 \%),{ }^{37}$ Sudan $(97.1 \%),{ }^{38}$ India $(64 \%),{ }^{11}$ Saudi Arabia $(72 \%),{ }^{39}$ another similar study in Saudi Arabia $(61.6 \%),{ }^{40}$ and Turkey $64.3 \%{ }^{41}$ The discrepancy between the current study and studies conducted in Jimma, southwest Ethiopia might be due to the majority of the participants in the studies conducted in Jimma being khat users. This could be the result of khat's effect on sleep latency and duration. ${ }^{33,42}$ The discrepancies with Nigeria were due to a different assessment tool.

Other discrepancies might be due to the sleep quality cut-off point of PSQI, a different measurement tool, and sociocultural differences, and that the setting in which the study was done in Turkey was in admitted DM patients.

This finding was in line with studies conducted in Malaysia $(47.2 \%),{ }^{43}$ Japan $(43.9 \%),{ }^{10}$ Korea $(49 \%),{ }^{44}$ and Iran $50.7 \% .{ }^{45}$ However, the finding of this study was higher than the studies conducted in Ethiopia (36.5\%), ${ }^{33}$ USA (29.7\%), ${ }^{46}$ Iraq $(35.3 \%),{ }^{47}$ Spain $(40 \%),{ }^{14}$ Iran $(38 \%),{ }^{48}$ Korea $(38.4 \%),{ }^{49}$ China $(33.6 \%),{ }^{50}$ and Nigeria $(27 \%) .{ }^{51}$ The discrepancy with studies done in the USA, Spain, Iraq, Korea, Iran, China and Nigeria might be due to socio-economic, psychosocial and behavioral factors. ${ }^{52-54}$ Another discrepancy might be due to study of composite sleep quality among three chronic diseases in Debre Markos, northwest Ethiopia.

In a multivariable logistic regression analysis, patients who drank alcohol were 2.45 times more likely to have poor sleep quality as compared with their counterparts. This was in line with the study conducted in Ethiopia. ${ }^{16}$ This might be because drinking more alcohol can negatively affect the quality of sleep..$^{55,56}$

Cigarette smoking had 6.26 times the odds of poor sleep quality than for those who had not smoked. This study was consistent with the studies conducted in 
Table 5 Factors Associated with Poor Sleep Quality Among Patients with DM at a Follow-Up Clinic at the UOGCSH, 2020 ( $\mathrm{n}=430)$

\begin{tabular}{|c|c|c|c|c|}
\hline \multirow[t]{2}{*}{ Variables } & \multicolumn{2}{|c|}{ Poor Sleep Quality } & \multicolumn{2}{|l|}{ OR 95\% Cl } \\
\hline & Yes & No & COR & AOR \\
\hline \multicolumn{5}{|l|}{ Alcohol Drinking } \\
\hline Yes & 40 & 25 & $1.98(1.55-3.40)$ & $2.45(1.28-4.69)^{*}$ \\
\hline No & 163 & 202 & I & \\
\hline \multicolumn{5}{|l|}{ Smoking status } \\
\hline Not smoked & 221 & 172 & 1 & \\
\hline Smoked & 6 & 31 & $6.64(2.71,18.27)$ & $6.27(2.04-19.21)^{* *}$ \\
\hline \multicolumn{5}{|l|}{ BMI } \\
\hline$<18.5 \mathrm{~kg} / \mathrm{m}^{2}$ & 7 & 12 & I & \\
\hline $18.5-24.9 \mathrm{~kg} / \mathrm{m}^{2}$ & 92 & 139 & $1.13(0.43-2.98)$ & $0.86(0.24-2.99)$ \\
\hline $25-29.9 \mathrm{~kg} / \mathrm{m}^{2}$ & 69 & 68 & $1.73(0.64-4.68)$ & I. $14(0.30-4.20)$ \\
\hline$\geq 30 \mathrm{~kg} / \mathrm{m}^{2}$ & 35 & 8 & $7.50(2.24-25.03)$ & $5.01(1.10-22.86)^{* *}$ \\
\hline \multicolumn{5}{|l|}{ Comorbidity } \\
\hline Yes & 143 & 106 & $2.72(1.82-4.05)$ & $1.80(1.10-2.96)^{*}$ \\
\hline No & 60 & 121 & I & \\
\hline \multicolumn{5}{|l|}{ Type DM } \\
\hline Type 2 & 177 & 152 & $3.36(2.05-5.5 \mathrm{I})$ & $2.16(1.04-4.48)^{*}$ \\
\hline Type I & 26 & 75 & 1 & \\
\hline \multicolumn{5}{|l|}{ Glycemic control } \\
\hline Good & 40 & 139 & I & 1 \\
\hline Poor & 126 & 125 & $3.56(2.16-5.7 I)$ & $2.6 \mathrm{I}(\mathrm{I} .8 \mathrm{I}-4.8 \mathrm{I})^{*}$ \\
\hline \multicolumn{5}{|l|}{ Depression } \\
\hline No & 32 & 231 & 1 & \\
\hline Yes & 119 & 37 & $23(13.8-39)$ & 9.93(4.84-20.38)* \\
\hline
\end{tabular}

Notes: *Indicates statistically significant $(p<0.05)$, **Highly statistically significant $(p<0.01)$.

Abbreviations: DM, diabetes mellitus; UoGCSH, University of Gondar Comprehensive Specialized Hospital.

Turkey, ${ }^{41}$ Japan, ${ }^{10}$ and Saudi Arabia. ${ }^{40,57}$ A possible reason might be due to the fact that smoking cigarettes has an effect on sleep latency and efficiency. ${ }^{58}$

Comorbidity was 1.80 times more likely to result in poor sleep quality as compared with no history of comorbidity. This study is consistent with studies conducted in Ethiopia ${ }^{16}$ and Turkey. ${ }^{41}$ This might be due to comorbidities resulting in poor glycemic control, more chronic complications and increased emotional disorder which can result in disturbed hemostasis and poor sleep quality. ${ }^{59}$

Having depression was 9.93 times more likely to result in poor sleep quality as compared with not reporting depressive symptoms. This finding was similar to studies conducted in Norway, ${ }^{60}$ China, ${ }^{61}$ and India. ${ }^{11}$ This might be due to common psychiatric disorders such as depression and anxiety being major factors in sleep disturbance among DM patients. ${ }^{62}$
Participants who had type 2 DM were 2.16 times more likely to have poor sleep quality as compared with those who had type $1 \mathrm{DM}$. This finding was similar to a study conducted in Spain. ${ }^{14}$ This might be because complications such as pain due to peripheral neuropathy commonly occur in type $2 \mathrm{DM}$, which can lead to sleep disturbance. Evidence also supports that, nocturia, sleep apnea, and restless leg syndrome can exacerbate sleep disruption. ${ }^{63}$

The odds of poor sleep quality was 2.61 times in patients with poor glycemic control than for those with good glycemic control. This finding was in line with studies done in $\mathrm{China}^{64}$ and Saudi Arabia ${ }^{39}$ This might be because patients with poor glycemic control may develop nocturia which leads to frequent sleep disturbance at night. ${ }^{65}$ Participants who had BMI $\geq 30 \mathrm{~kg} / \mathrm{m}^{2}$ were 5 times more likely to have poor sleep quality as compared with their counterparts. This study was consistent with the study conducted in Japan. ${ }^{10}$ This might be due to higher 
BMI leading to less physical activity, more diabetes complications and sleep disturbance. ${ }^{11}$

\section{Conclusion}

The finding of this study showed that nearly half of participants had poor sleep quality. Variables such as drinking alcohol, havin a history of smoking, comorbidities, type 2 $\mathrm{DM}$, poor glycemic control, depression and BMI $\geq 30 \mathrm{~kg} /$ $\mathrm{m}^{2}$ were factors in poor sleep quality. Policymakers ought to incorporate a sleep quality assessment checklist in routine DM follow-up clinics. Health-care professionals ought to be give attention to comorbidities with DM. Early management services including health education as a part of the routine management of diabetes mellitus can improve poor sleep quality. Special education is also needed in patients who drink alcohol, are cigarette smokers, have comorbidities or report symptoms of depression.

\section{Limitation of the Study}

Recall bias was a limitation in this study due to selfreporting in the questionnaire by participants. The participants also might respond with only socially acceptable answers. The cross-sectional nature of the study cannot rule out the cause-effect relationship.

\section{Abbreviations}

AOR, adjusted odds ratio; BMI, body mass index; CHF, congestive heart failure; $\mathrm{Cl}$, confidence interval; $\mathrm{COR}$, crude odds ratio; DM, diabetes mellitus; FBG, fasting blood glucose; HTN, hypertension; OPD, outpatient department; PHQ, Patient Health Questionnaire; SD, standard deviation; PSQI, Pittsburgh Sleep Quality Index; SPSS, Statistical Package Social Science; UOGSH, University of Gondar Specialized Hospital; USA, United States; WHO, World Health Organization.

\section{Data and Material Availability}

The raw data are available from one of the corresponding authors on rational request.

\section{Ethical Approval and Consent}

The study was performed based on the ethical standards of the declaration of Helsinki. Ethical clearance was obtained from the institutional ethical review committee of the School of Nursing and College of Health Science of University Gondar with ethical clearance letter reference number Rf.No:S/N2012/06/2012. An official permission letter was obtained from the University of Gondar hospital administration. After understanding the purpose of the study, written informed consent was obtained from study participants. Confidentiality of participants' information was kept.

\section{Consent to Publication}

Not applicable.

\section{Acknowledgment}

Our deepest gratitude goes to University of Gondar for all expenses of this research work and to the study participants who participated in this research. The authors also have great appreciation for the data collectors and supervisors for their contribution to this paper.

\section{Author Contributions}

All authors made a significant contribution to the work reported, whether that is in the conception, study design, execution, acquisition of data, analysis and interpretation or in all these areas; took part in drafting, revising or critically reviewing the article; gave final approval of the version to be published; have agreed on the journal to which the article has been submitted; and agree to be accountable for all aspects of the work.

\section{Funding}

The study was supported by the University of Gondar College of medicine and health science. The funder had no role in design, data collection, analysis, drafting, manuscript, preparation and publication of this paper.

\section{Disclosure}

The authors report no conflicts of interest for this work.

\section{References}

1. Habtewold TD, Tsega WD, Wale BY. Diabetes mellitus in outpatients in Debre Berhan referral hospital, Ethiopia. $J$ Diabetes Res. 2016;2016:1-6. doi:10.1155/2016/3571368

2. Shiberu T. Prevalence and Factors Associated with Diabetes Retinopathy Among Type 2 Diabetes Patients at Tikur Anbesa Specialized Hospital Addis Ababa, Ethiopia, 2018. Addis Ababa University; 2018.

3. Darraj A, Mahfouz MS, Alsabaani A, Sani M, Alameer A. Assessment of sleep quality and its predictors among patients with diabetes in Jazan, Saudi Arabia. Diabetes Metab Syndr Obes. 2018;11:523. doi:10.2147/DMSO.S178674

4. Bishu KG, Jenkins C, Yebyo HG, Atsbha M, Wubayehu T, Gebregziabher M. Diabetes in Ethiopia: a systematic review of prevalence, risk factors, complications, and cost. Obes Med. 2019;15:100132. doi:10.1016/j.obmed.2019.100132 
5. Iyer SR. Sleep and type 2 diabetes mellitus-clinical implications. JAPI. 2012;60:43.

6. Guyton AC. Tratado De Fisiologia Médica. Brasil: Elsevier; 2006.

7. Leproult R, Van Cauter E. Role of Sleep and Sleep Loss in Hormonal Release and Metabolism. Pediatric Neuroendocrinology. 17. Karger Publishers; 2010:11-21.

8. Rocha BR, Behlau M. The influence of sleep disorders on voice quality. $J$ Voice. 2018;32(6):771.e1-e13. doi:10.1016/j. jvoice.2017.08.009

9. Grandner MA, Seixas A, Shetty S, Shenoy S. Sleep duration and diabetes risk: population trends and potential mechanisms. Curr Diab Rep. 2016;16(11):106.

10. Narisawa H, Komada Y, Miwa T, et al. Prevalence, symptomatic features, and factors associated with sleep disturbance/insomnia in Japanese patients with type-2 diabetes. Neuropsychiatr Dis Treat. 2017;13:1873. doi:10.2147/NDT.S134814

11. Khandelwal D, Dutta D, Chittawar S, Kalra S. Sleep disorders in type 2 diabetes. Indian J Endocrinol Metab. 2017;21(5):758. doi:10.4103/ ijem.IJEM 15617

12. Farabi SS. Type 1 diabetes and sleep. Diabetes Spectr. 2016;29 (1):10-13. doi:10.2337/diaspect.29.1.10

13. Lou P, Zhang P, Zhang L, et al. Effects of sleep duration and sleep quality on prevalence of type 2 diabetes mellitus: a 5-year follow-up study in China. Diabetes Res Clin Pract. 2015;109(1):178-184. doi:10.1016/j.diabres.2015.04.012

14. Lecube A, Sánchez E, Gómez-Peralta F, et al. Global assessment of the impact of type 2 diabetes on sleep through specific questionnaires. PLoS One. 2016;11(6):e0157579. doi:10.1371/journal.pone. 0157579

15. Sokwalla SMR, Joshi MD, Amayo EO, Acharya K, Mecha JO, Mutai KK. Quality of sleep and risk for obstructive sleep apnoea in ambulant individuals with type 2 diabetes mellitus at a tertiary referral hospital in Kenya: a cross-sectional, comparative study. $B M C$ Endocr Disord. 2017;17(1):7. doi:10.1186/s12902-017-0158-6

16. Jemere T, Mossie A, Berhanu H, Yeshaw Y. Poor sleep quality and its predictors among type 2 diabetes mellitus patients attending Jimma University Medical Center, Jimma, Ethiopia. BMC Res Notes. 2019;12(1):488. doi:10.1186/s13104-019-4531-6

17. Surani S, Brito V, Surani A, Ghamande S. Effect of diabetes mellitus on sleep quality. World J Diabetes. 2015;6(6):868. doi:10.4239/wjd. v6.i6.868

18. Rajendran A, Parthsarathy S, Tamilselvan B, Seshadri KG, Shuaib M. Prevalence and correlates of disordered sleep in southeast asian indians with type 2 diabetes. Diabetes Metab J. 2012;36(1):70-76. doi:10.4093/dmj.2012.36.1.70

19. Adams RJ, Appleton SL, Taylor AW, et al. Sleep health of Australian adults in 2016: results of the 2016 Sleep Health Foundation national survey. Sleep Health. 2017;3(1):35-42. doi:10.1016/j.sleh.2016.11.005

20. Bakhsh LA, Adas AA, Murad MA, et al. Awareness and knowledge on hypertension and its self-care practices among hypertensive patients in Saudi Arabia. Ann Int Med Den Res. 2017;3(5):58-62.

21. Tachebele B, Abebe M, Addis Z, Mesfin N. Metabolic syndrome among hypertensive patients at University of Gondar Hospital, North West Ethiopia: a cross sectional study. BMC Cardiovasc Disord. 2014;14(1):177. doi:10.1186/1471-2261-14-177

22. Nurses' knowledge towards pressure ulcer and its associated factors at Hawassa University Comprehensive Specialized Hospital Hawassa, Ethiopia, 2018. preprint. In Review, 2019 2019/08/25/. Report No.

23. Salahuddin M, Maru TT, Kumalo A, Pandi-Perumal SR, Bahammam AS, Manzar MD. Validation of the Pittsburgh sleep quality index in community dwelling Ethiopian adults. Health Qual Life Outcomes. 2017;15(1):58. doi:10.1186/s12955-017-0637-5

24. Fiseha T, Alemayehu E, Kassahun W, Adamu A, Gebreweld A. Factors associated with glycemic control among diabetic adult out-patients in Northeast Ethiopia. BMC Res Notes. 2018;11(1):316. doi:10.1186/s13104-018-3423-5
25. Gelaye B, Williams MA, Lemma S, et al. Validity of the patient health questionnaire-9 for depression screening and diagnosis in East Africa. Psychiatry Res. 2013;210(2):653-661. doi:10.1016/j. psychres.2013.07.015

26. Dadi AF, Dachew BA, Kisi T, Yigzaw N, Azale T. Anxiety and associated factors among prisoners in North West of Amhara Regional State, Ethiopia. BMC Psychiatry. 2016;16(1):83. doi:10.1186/s12888-016-0792-y

27. Valderas JM, Starfield B, Sibbald B, Salisbury C, Roland M. Defining comorbidity: implications for understanding health and health services. Ann Fam Med. 2009;7(4):357-363. doi:10.1370/afm.983

28. Crum-Cianflone NF, Roediger MP, Moore DJ, et al. Prevalence and factors associated with sleep disturbances among early-treated HIV-infected persons. Clin Infect Dis. 2012;54(10):1485-1494.

29. Regassa LD, Gete YK, Mekonnen FA, Remuzzi G. Time to acute kidney injury and its predictors among newly diagnosed Type 2 diabetic patients at government hospitals in Harari Region, East Ethiopia. PLoS One. 2019;14(5):e215967. doi:10.1371/journal. pone. 0215967

30. Zekewos A, Loha E, Egeno T, Wubshet K, Merga Z. Prevalence of diabetes mellitus and associated factors in Southern Ethiopia: a community based study. Ethiop J Health Sci. 2018;28(4).

31. Girardin Jean-Louis KM, Weber BE, Aouizerat AM, et al. Insomnia symptoms and HIV infection among participants in the women's interagency HIV study. Sleep. 2012;35(1):131-137.

32. Berhanu H, Mossie A, Tadesse S, Geleta AD. Prevalence and Associated Factors of Sleep Quality Among Adults in Jimma Town, Southwest Ethiopia: A Community-Based Cross-Sectional Study. Hindawi; 2018:10.

33. Berhanu H, Mossie A, Tadesse S, Geleta D. Prevalence and associated factors of sleep quality among adults in Jimma Town, Southwest Ethiopia: a community-based cross-sectional study. Sleep Disord. 2018;2018:1-10. doi:10.1155/2018/8342328

34. Tiirikainen K, Haravuori H, Ranta K, Kaltiala-Heino R, Marttunen M. Psychometric properties of the 7-item Generalized Anxiety Disorder scale (GAD-7) in a large representative sample of Finnish adolescents. Psychiatry Res. 2019;272:30-35. doi:10.1016/j. psychres.2018.12.004

35. Chattu VK, Chattu SK, Burman D, Spence DW, Pandi-Perumal SR, editors. The Interlinked Rising Epidemic of Insufficient Sleep and Diabetes Mellitus. Healthcare: Multidisciplinary Digital Publishing Institute; 2019.

36. Chasens ER, Sereika SM, Burke LE, Strollo PJ, Korytkowski M. Sleep, health-related quality of life, and functional outcomes in adults with diabetes. Appl Nurs Res. 2014;27(4):237-241. doi:10.1016/j. apnr.2014.02.006

37. Chasens ER, Morris JL, Strollo PJ, Sereika SM, Burke LE, Korytkowski M. Gender differences in the response to impaired sleep in adults with diabetes. Behav Sleep Med. 2016;14 (4):457-466. doi:10.1080/15402002.2015.1017100

38. Mirghani H. Sleep quality effects on glycemic control among Sudanese patients with type 2 diabetes - a case-control study. Basic Res J Med Clin Sci. 2015;4:258-261.

39. Alshenghiti AM, Alsadran FF, Alzahrani RA, Assiri I. Sleep quality among type 2 Saudi diabetics. Med J Cairo Univ. 2016;167-171.

40. Mahfouz MS, Sani M Assessment of sleep quality and its predictors among patients with diabetes in Jazan, Saudi arabia. 2018.

41. Keskin A, Ünalacak M, Bilge U, et al. Effects of sleep disorders on hemoglobin Alc levels in type 2 diabetic patients. Chin Med J. 2015;128(24):3292. doi:10.4103/0366-6999.171415

42. Abebe M, Kindie S, Adane K. Adverse health effects of khat: a review. Fam Med Med Sci Res. 2015;4(1):2-5.

43. Razali R, Ariffin J, Aziz AFA, Puteh SEW, Wahab S, Daud TIM. Sleep quality and psychosocial correlates among elderly attendees of an urban primary care centre in Malaysia. Neurol Asia. 2016;21 (3). 
44. Cho E-H, Lee H, Ryu OH, Choi MG, Kim S-W. Sleep disturbances and glucoregulation in patients with type 2 diabetes. $J$ Korean Med Sci. 2014;29(2):243-247. doi:10.3346/jkms.2014.29.2.243

45. Khosravan S, Alami A, Golchin Rahni S. Prevalence of sleep disorder in type 2 diabetes Mellitus patients and it's related factors. $J$ Res Health. 2015;5(3):298-304.

46. LeBlanc ES, Smith NX, Nichols GA, Allison MJ, Clarke GN. Insomnia is associated with an increased risk of type 2 diabetes in the clinical setting. BMJ Open Diabetes Res Care. 2018;6(1): e000604. doi:10.1136/bmjdrc-2018-000604

47. Al-Humairi AK, Hassan NK. Impact of sleep quality on glycemic control in type 2 diabetes mellitus. Med J Babylon. 2018;15 (4):369-375. doi:10.4103/MJBL.MJBL_80_18

48. Shamshirgaran SM, Ataei J, Malek A, Iranparvar-Alamdari M, Aminisani N. Quality of sleep and its determinants among people with type 2 diabetes mellitus in Northwest of Iran. World J Diabetes. 2017;8(7):358. doi:10.4239/wjd.v8.i7.358

49. Shim U, Lee H, Oh J-Y, Sung Y-A. Sleep disorder and cardiovascular risk factors among patients with type 2 diabetes mellitus. Korean J Intern Med. 2011;26(3):277. doi:10.3904/kjim.2011.26.3.277

50. Lou P, Qin Y, Zhang P, et al. Association of sleep quality and quality of life in type 2 diabetes mellitus: a cross-sectional study in China. Diabetes Res Clin Pract. 2015;107(1):69-76. doi:10.1016/j. diabres.2014.09.060

51. Obaseki DO, Kolawole BA, Gomerep SS, et al. Prevalence and predictors of obstructive sleep apnea syndrome in a sample of patients with type 2 Diabetes Mellitus in Nigeria. Niger Med J. 2014;55(1):24. doi:10.4103/0300-1652.128154

52. Madmoli M, Madmoli M, Aliabad MA, Khodadadi M, Ahmadi FP. A systematic review on the impact of empowerment in improving self-care behaviors and some other factors in diabetic patients. Int J Health Biol Sci. 2019;2(1):11-16.

53. Bains SS, Egede LE. Associations between health literacy, diabetes knowledge, self-care behaviors, and glycemic control in a low income population with type 2 diabetes. Diabetes Technol Ther. 2011;13(3):335-341. doi:10.1089/dia.2010.0160

54. Agrigoroaei S, Lachman ME. Cognitive functioning in midlife and old age: combined effects of psychosocial and behavioral factors. J Gerontol Series B. 2011;66(suppl_1):i130-i40. doi:10.1093/geronb/ gbr017
55. Reda AA, Y. Wondmagegn B, Wondmagegn BY, Wondmagegn BY. Prevalence and determinants of khat (Catha edulis) chewing among high school students in Eastern Ethiopia: a crosssectional study. PLoS One. 2012;7(3):e33946. doi:10.1371/journal.pone.0033946

56. Britton A, Fat LN, Neligan A. The association between alcohol consumption and sleep disorders among older people in the general population. Sci Rep. 2020;10(1):1-7. doi:10.1038/s41598-020-62227-0

57. Al-Tannir MA, Kobrosly SY, Al-Badr AH, Salloum NA, Altannir YM, Sakkijha HM. Characterizing sleeping habits and disturbances among Saudi adults. Saudi Med J. 2016;37(12):1372. doi: $10.15537 / \mathrm{smj} .2016 .12 .17373$

58. Lemma SPS, Tarekegn YA, Tarekegn YA, et al. The epidemiology of sleep quality, sleep patterns, consumption of caffeinated beverages, and cigarete use among Ethiopian college students. Sleep Disord. 2012;2012:1-11. doi:10.1155/2012/583510

59. Pinheiro T, Thomas T, Devaraj U, Ramachandran P, Maheswari KU. Prevalence of Restless Leg Syndrome and quality of sleep in type 2 diabetics. J Diabetes Complications. 2020;34:107727. doi:10.1016/j. jdiacomp.2020.107727

60. Fetveit A, Straand J, Bjorvatn B, Kristoffersen ES. Self-reported sleeplessness in 12,655 persons living in the north of Norway: the Tromsø Study. Sleep Sci. 2019;12(3):147. doi:10.5935/19840063.20190070

61. Zhang P, Lou P, Chang G, et al. Combined effects of sleep quality and depression on quality of life in patients with type 2 diabetes. BMC Fam Pract. 2016;17(1):40. doi:10.1186/s12875-016-0435-x

62. Xiaojie Huang HL, Meyers K, Xia W, et al. Burden of sleep disturbances and associated risk factors: China. 2017.

63. Perfect MM. Sleep-related disorders in patients with type 1 diabetes mellitus: current insights. Nat Sci Sleep. 2020;12:101. doi:10.2147/ NSS.S152555

64. Zhu B-Q, Li X-M, Wang D, Yu X-F. Sleep quality and its impact on glycaemic control in patients with type 2 diabetes mellitus. Int J Nurs Sci. 2014;1(3):260-265. doi:10.1016/j.ijnss.2014.05.020

65. Cunha M, Zanetti ML, Hass VJ. Sleep quality in type 2 diabetics. Rev Lat Am Enfermagem. 2008;16(5):850-855. doi:10.1590/S010411692008000500009

\section{Publish your work in this journal}

Diabetes, Metabolic Syndrome and Obesity: Targets and Therapy is an international, peer-reviewed open-access journal committed to the rapid publication of the latest laboratory and clinical findings in the fields of diabetes, metabolic syndrome and obesity research. Original research, review, case reports, hypothesis formation, expert opinion and commentaries are all considered for publication. The manuscript management system is completely online and includes a very quick and fair peer-review system, which is all easy to use. Visit http://www.dovepress.com/testimonials.php to read real quotes from published authors.

Submit your manuscript here: https://www.dovepress.com/diabetes-metabolic-syndrome-and-obesity-targets-and-therapy-journal 